\title{
BokSmart: Preventive rehabilitation for rugby injuries to the lower back and core
}

\author{
Neil Hopkins (BSc(Med) (Hons) Exercise Science (Biokinetics)) ${ }^{1}$ \\ Wayne Viljoen (PhD) $)^{2}$ \\ ${ }^{1}$ Private Biokineticist: Murphy \& Hopkins Biokineticists \\ ${ }^{2}$ Manager: BokSmart National Rugby Safety Programme
}

\begin{abstract}
Background. The low back is an integral part of the entire movement chain as it functions as part of a complex network of the skeletal, muscular and nervous system. Eighty to $90 \%$ of acute low back pain episodes dissipate within $8-12$ weeks regardless of any intervention, but $5-10 \%$ regress into chronic low back pain. As a result of its undistinguished aetiology, the treatment for low back pain remains controversial. Treatment options for low back pain include the following: analgesics, muscle relaxants, antidepressants, nonsteroidal anti-inflammatory drugs, epidural steroid injections, manipulation, back schools, electromyographic biofeedback, traction, orthoses, behaviour therapy, transcutaneous electrical nerve stimulation, acupuncture, and exercise therapy.

Results. Therapeutic exercises for low back pain have been shown in 6 different randomised controlled trials to be beneficial in reducing pain by up to $60 \%$ and improving functional ability by up to $47 \%$. Furthermore, a Cochrane review on low back pain found strong evidence that exercise therapy is an effective intervention in the treatment of low back pain. When prescribing exercises for an individual with low back pain the following goals need to be considered: (i) improve performance in endurance activities; (ii) improve muscular strength around the spine; (iii) eliminate any impairments in spinal flexibility; (iv) reduce the intensity of the pain being experienced by the individual; and $(v)$ reduce back pain-related disability. A rugby player will have increased core stability/strength and a reduced risk of injury if the internal support mechanisms of the spine have been conditioned to resist distortion or injury from external forces. Not only will improved core
\end{abstract}

\section{CORRESPONDENCE:}

Neil Hopkins

Murphy \& Hopkins Biokineticists

Vincent Pallotti Hospital, Rehabilitation and Hydrotherapy Centre Dick Williamson Medical Centre, Lower Ground Level

Pinelands 7405

South Africa

Tel.: +27 (21) 5323203

E-mail: neilhopkins.sa@gmail.com stability benefit players on the field during matches or practices, it will also assist in preventing unnecessary injuries during weight training and pre-season conditioning.

Conclusion. Exercise programmes which combine core stability with general strength training should be prescribed for rugby players to prepare them for the level of impact involved in the game as well as for sport-related weight training and non-sport-related daily activities.

\section{Introduction}

Rugby is a full-contact sport which has one of the highest injury rates when compared with other team sports. ${ }^{9}$ Although injuries are expected from any high-speed and high-impact situation, steps have been taken to minimise the high injury rates within rugby. Law changes, cutting down on foul play, improving protective equipment as well as increasing the emphasis on proper conditioning are but a few of the steps taken with the goal of reducing the risk of injury. Due to the increase in injury risk a considerable amount of research has been conducted on the nature and cause of injuries in rugby, and how they can be prevented. Nevertheless, there is a need for further examination of specific game events associated with higher injury rates. ${ }^{9}$ Although a significant amount of research is concerned with the risk of spinal injury associated with playing rugby, ${ }^{17}$ further research is required around injuries to the lower back and core.

\section{Background}

Trends in the nature of injury in rugby have changed since 1995 as a result of numerous modifications to the laws combined with the creation of professionalism within the sport. ${ }^{9}$ The changes since 1995 have been associated with some negative consequences such as an increase in injury risk for both professional and amateur games. ${ }^{38}$ However, the financial rewards associated with professionalism can in some ways be linked to an increase in participation and hence an increase in the rugby player population. ${ }^{6}$ The increase in the number of individuals playing rugby has therefore resulted in an increase in the population at risk of rugby-related injuries.

The head, rib cage, pelvis, and spinal column form the central component of the skeleton. One of the primary functions of this central component is to absorb and dissipate forces which act upon the body; this role is mainly fulfilled by the spine and the muscles which support it. An increased possibility of injury occurs if there is a dysfunction in the protective and load-distributing capacity of the spine. This is particularly evident in the lumbar spine, which can be seen as the building block for the low back region. The low back is an integral part of the entire movement chain as it functions as part of 
a complex network of the skeletal, muscular and nervous systems. ${ }^{40}$ Countless research hours have been spent trying to determine the exact cause of low back pain, but numerous cases of low back pain remain unexplained as a result of the complex relationship between the brain, bones, muscles and ligaments.

Low back injuries are not a phenomenon exclusive to rugby players or any other athlete population; it is a global phenomenon. This is evident from the large number of low back-related disorders within normal populations. Low back pain affects a large number of sedentary individuals and is the greatest cause of absence from work, or loss in work productivity. ${ }^{47}$ In South Africa, this is evident by the fact that physiotherapists treat at least 6 patients with low back pain per week, ${ }^{47}$ with $60-80 \%$ of the population experiencing back pain at some time in their life. ${ }^{46}$ In the majority of cases the mechanical cause of low back pain will differ between sedentary and athletic populations. Normal populations tend to get lifestyleassociated back pain whereas rugby players tend to suffer from back pain which is associated with exercise, rather than the lack thereof. However, the structures affected in the low back are the same in both population groups, as their human anatomy does not differ.

Eighty to $90 \%$ of acute low back pain episodes dissipate within 8 12 weeks regardless of any intervention; ${ }^{23}$ however, $5-10 \%$ regress into chronic low back pain. ${ }^{31}$ Used in this sense the term chronic does not refer to the intensity of the pain but rather to the extent of its duration. Individuals who suffer from low back pain for longer than 12 weeks are considered to have chronic low back pain. ${ }^{1}$ Chronic low back pain appears to be caused by a multiple combination of risk factors which vary between individuals. ${ }^{30}$

There is a vast amount of literature on low back pain, with over 5000 published articles, ${ }^{3}$ but there are very few studies conducted on chronic low back pain that are randomised or controlled. ${ }^{22} \mathrm{~A}$ considerable amount of the available research has tried to establish whether any functional or anatomical differences exist between individuals who suffer from chronic low back pain and those who do not. ${ }^{16}$ Current research has also been aimed at determining whether low back pain is the result of suboptimal neuromuscular control under dynamic conditions. ${ }^{41}$ The results of the research around the low back have been inconclusive, partly due to the fact that the spine and its associated structures are complex in nature and therefore difficult to study.

\section{Most common injuries}

Injury to the spine in rugby occurs mainly to the cervical spine; however there is also a risk of injury to the low back and its supporting structures. ${ }^{17}$ There are numerous mechanical forces involved in producing spinal injuries and the most common injuries to the spine occur as a result of one, or a number, of these forces acting on the lumbar spine or the surrounding tissue. ${ }^{36}$ These forces can be broken down into: flexion forces (forward bending), extension forces (backward bending), rotation forces (twisting), shear forces (one vertebra sliding in relation to another), and compression forces (vertical pressure). ${ }^{36}$ It is often the extremes of range or force that result in injury; however, even a relatively small force can result in an injury if the spine is not adequately supported. The most effective way to categorise sport-related injuries to the low back is to break them down into the structures affected. These include: fractures to the spinal column, injury to the interverterbral disk, ligament strain, joint inflammation, and muscular spasm. ${ }^{10}$ Other less common injuries also occur, which is why an accurate diagnosis is essential before treatment.

\section{Mechanism of injury}

The research on the incidence of injury shows that the majority of injuries in rugby occur when tackling or being tackled. ${ }^{9}$ Tackles have been found to be the rugby event responsible for the greatest number of injuries as they are by far the most common contact event in the game. As a result they account for the greatest cause of all injuries, followed by the ruck/maul. ${ }^{38}$ There are various types of tackles, each with their own risk for the player tackling and the player being tackled. Dangerous tackles include blind tackles, gang (group) tackles, and spear tackles. Blind tackles occur when the player is tackled from behind or from a position outside of their range of vision (in the player's peripheral vision). ${ }^{19}$ There is a higher risk of injury with this kind of tackle as the player is often caught unaware, and is often unprepared for the impact. The tackle with the greatest risk of spinal injury is the spear tackle, which has subsequently been banned from rugby as it constitutes foul play. ${ }^{38}$ Further studies have also shown that although tackles cause the greatest number of injuries it is collisions which are more likely to result in injury. ${ }^{18}$ Even though there are fewer collisions during a game, they are more likely to result in an injury than a tackle.

The forces involved in scrumming and the positioning of the players have always been a concern when it comes to spinal injuries. ${ }^{37}$ However, thanks to a greater awareness of the dangers involved in scrumming, the risk of spinal injury in the scrum has decreased. ${ }^{20}$ Due to improvements in refereeing and laws governing the scrum, the number of injuries as a result of scrumming has decreased in comparison with the number of injuries sustained during the ruck and maul phases. ${ }^{38}$ Nevertheless scrums are inherently dangerous because the players are placed into positions that have the potential to compromise the safety of the spine. As a result, scrums carry a much greater risk of injury than tackles. ${ }^{18}$ The forces involved in scrumming not only have the potential for severe spinal injuries but they place an increased amount of strain on the low back, especially on the discs between the lumbar vertebrae. The majority of research up until now has focused on the incidence of traumatic injuries to the spine, especially the cervical spine, but there is also a risk of non-traumatic, overuse injuries ${ }^{17}$. Research has also indicated that not only do rugby players have a high risk of spinal injury from game-related activities, but as a result of weight-training activities as well. ${ }^{17}$

There is no consensus on the most dangerous position in rugby, because certain positions carry different risks for different injuries. It is safe to assume that the positions that carry the greatest risk of injury are those involved with the most contact and the greatest number of tackles, such as the loose forwards and certain players in the backline. Some players have a greater risk of injury to the low back as a result of game situations that are unique to their position. Players who are involved in a greater number of contact situations will obviously have a greater risk, along with players in dangerous positions in the scrum, such as the front row. One study shows that with regards to low back injuries, hookers and flyhalves have the highest incidence of injuries, hookers and outside centres have the greatest risk of injury, while the greatest severity of injury was experienced by locks and flankers. ${ }^{8}$ The injury rate to the low back is the same for forwards and backs; however, the majority of low back-related injuries for forwards occurred because of ruck and maul situations whereas backline players were mainly injured in tackle situations. ${ }^{8}$ The severity, however, of low back injuries between forwards and backs differed. Low back injuries in backline players, caused by excessive twisting and turning while tackling or being tackled, were more severe and resulted in more time off. ${ }^{8}$ 
The rate of injury in rugby has been found to be directly proportional to the level of the game but inversely proportional to the age of the player. ${ }^{6}$ What this means is that more injuries occur in higher teams (1st team) and older age groups and fewer injuries occur in lower teams (5th team) and junior levels of rugby. It has also been found that rugby matches carry a far greater risk of injury than practices especially matches played at the start of the season. ${ }^{11}$ Research has indicated that most injuries occur at the start of the season or during the first few weeks following a break mid-season. ${ }^{43}$

A generally accepted principle in the discipline of sports medicine is that the greatest predictor of a future injury is a previous injury. ${ }^{10}$ This is an important finding because the return to sport phase following an injury will carry a similar level of risk to the early phases of the rugby season. Most injuries result in time off, with injuries caused by tackles resulting in the greatest amount of time off. ${ }^{8}$

It is imperative that injured rugby players be fully recovered and conditioned before returning to game situations, in order to avoid further injury, further time off, and possibly a reduction in length of their rugby careers. ${ }^{35}$

\section{Spinal stability}

Stability of the lumbar spine requires passive stiffness through bone and ligament structures and active stiffness through muscle contraction. ${ }^{40}$ The passive structures provide stability through their structural composition and hence cannot produce movement. Passive structures such as ligaments are only effective at the end of range to prevent excessive segmental movement of the spine. ${ }^{40}$ The active structures provide stability by contracting or tightening and play a predominant role in maintaining lumbar spine stability throughout the entire range of movement. ${ }^{40}$ These active structures are made up primarily of muscles located around the lumbar spine, such as the transversus abdominus and multifidus. The abdominal muscles, which are fundamental to the active maintenance of spinal stability, include the internal oblique, external oblique, transversus abdominus, ${ }^{5}$ and to some degree rectus abdominus.

Essentially spinal stability requires the contraction of key muscles, individually as well as in co-operation with each other, to maintain posture and intersegmental control. To visualise this intricate stabilising system, imagine the spine as a tent pole and the muscles as the supporting guy ropes. ${ }^{2}$ If the tent pole is placed upright on the ground without any external support it will fall over. The role of the guy ropes is to provide support to the otherwise unstable tent pole. The more guy ropes the more stable the tent pole, just as without the guy ropes the tent pole will fall over.

Segmental stability between the vertebrae is primarily provided by local muscles which have influence over inter-segmental control due to their attachments on the lumbar spine. ${ }^{7}$ Behavioural evidence has shown that the transversus abdominus can be classified as one of these local muscles and therefore makes up an important part of the core-stabilising musculature. ${ }^{24}$ Transversus abdominus has an influence on segmental stability in a general manner, but this stability is not direction specific. ${ }^{25}$ This implies that the transversus abdominus plays a role in multidirectional stability and thus protects the spine from forces acting in a multitude of directions. Research has shown that transversus abdominus is the first muscle to activate prior to limb movement, but is delayed in individuals with low back pain. $^{27}$ The importance of activation prior to movement is that it generates spinal stiffness, and therefore prevents hypermobility. ${ }^{27}$

The spinal stabilising system is made up of three subsystems. ${ }^{40}$ The three subsystems are made up of the spinal column, which provides intrinsic stability, the muscles which provide dynamic stability, and the neural control unit, which functions to co-ordinate the muscular response. ${ }^{40}$ This muscular subsystem has a significant role to play, as correct muscle activation is essential in the maintenance of posture and intersegmental control during movement. ${ }^{27}$ The neural control unit determines the requirements for stability and generates the appropriate muscle patterns to provide the required stability. $^{41}$ This is important in preparation for predictable forces (i.e. voluntary limb movement), as well as to initiate responses to unexpected perturbations (i.e. external forces which are not under voluntary control). ${ }^{13}$ A further mechanism which assists in spinal stability is achieved by increasing the intra-abdominal pressure via the interaction between the muscular and nervous systems. ${ }^{12}$

\section{Spinal instability}

By nature the spine is classified as being unstable as a result of its structure. ${ }^{27}$ A large number of mechanically related back pain cases may occur as a result of this inherent instability around the lumbar spine. ${ }^{4}$ The stability of the lumbar spine is challenged on a day-today basis by a diverse range of external forces and loads acting upon it. ${ }^{7}$ These external forces are increased in a contact sport such as rugby. The impact involved with scrumming, tackling, diving, and collisions puts increased strain on the spine and the stabilising structures which support it.

Spinal instability is classified into two categories: mechanical instability and clinical instability. The inability of the spine to accommodate external forces is termed a mechanical instability whereas clinical instability occurs as a result of pain or inadequate neural stimulation. ${ }^{41}$ Mechanical stability of the spine is provided by the spinal column itself as well as the surrounding muscles, especially when there are external forces acting on the spine during movement and loading. 41

Most cases of back pain occur as a result of excessive and uncontrolled movement of the lumbar spine. Under normal conditions stabilising subsystems work in harmony to provide mechanical stability for the spine. ${ }^{24}$ However, in the presence of pain, or when there is a dysfunction with the low back, there is a loss in the ability of the stabilising subsystems to fulfil their role. ${ }^{28}$ The presence of pain reduces the optimal functioning of the central nervous system and therefore the ability to maintain the muscular component of spinal stability and control. Under normal conditions the subsystems work in harmony to provide mechanical stability to the spine; however, with pathology such as in low back pain there is a loss in the ability of these subsystems to fulfil their role. ${ }^{24}$ As mentioned, this is especially the case with the neural control unit. The presence of pain reduces the optimal functioning of the neural control unit, more specifically the central nervous system and therefore the ability to maintain the active component of spinal stability. ${ }^{24}$

Individuals without any dysfunction have been shown to pre-activate their deeper abdominal muscles to aid in spinal stabilisation. ${ }^{27}$ However, in attempting to increase the spinal stiffness around the neutral spine, individuals with chronic low back pain have shown a predisposition to increase total trunk muscle activity. ${ }^{29}$ These individuals are not successful in their attempt to increase trunk stability at a local level (i.e. through transversus abdominus activation) as they rely mainly on global muscle recruitment (i.e. rectus abdominus activation) for stabilisation rather than more functional synergist patterns of stabilising muscles. ${ }^{24}$ This has a negative consequence because when there is an increase in the activity of the global muscle system there is a concomitant decrease in the deeper local muscle system. ${ }^{24}$ 
Dynamic control of stability around the spine is achieved through contraction of specific muscles (i.e. the transversus abdominus) prior to movement. ${ }^{24}$ This pre-activation controls the positioning of the centre of gravity within the base of support. ${ }^{27}$ In healthy, pain-free individuals the transversus abdominus muscle is the first trunk muscle to activate prior to limb movement and, in this capacity, contributes towards enhancing trunk stability. ${ }^{27}$ Based on the hypothesis that the transversus abdominus contributes to a separate aspect of lumbar stability, it is predicted that the central nervous system may control components of spinal stability independently. 25

\section{Rehabilitation of low back pain}

As a result of its undistinguished aetiology, the treatment for low back pain remains controversial. ${ }^{34}$ Treatment options for low back pain include the following: analgesics, muscle relaxants, antidepressants, non-steroidal anti-inflammatory drugs, epidural steroid injections, manipulation, back schools, electromyographic biofeedback, traction, orthoses, behaviour therapy, transcutaneous electrical nerve stimulation, acupuncture, and exercise therapy. ${ }^{49}$

The prevailing medical approach to the treatment of low back pain appears to consider a return to normal active daily living a more important clinical goal than pain relief. ${ }^{1}$ There is no evidence to suggest that regular exercise increases the risk of degeneration or future back pain, and as a result controlled exercise can be seen as being safe for individuals who suffer from low back pain. ${ }^{42}$ In fact, a lack of exercise may even play an important role in the onset of low back pain. ${ }^{15}$ Carefully selected exercises can be useful for reducing back pain intensity and back pain-related disability, and have also been associated with improved functional capacity. ${ }^{42}$ Therapeutic exercises for low back pain have been shown in 6 different randomised controlled trials to be beneficial in reducing pain by up to $60 \%$ and improving functional ability by up to $47 \%$. $^{3}$ A Cochrane review on low back pain found strong evidence that exercise therapy is an effective intervention in the treatment of low back pain. ${ }^{49}$

When prescribing exercises for an individual with low back pain the following goals need to be considered: (i) improve performance in endurance activities; (ii) improve muscular strength around the spine; (iii) eliminate any impairments in spinal flexibility; (iv) reduce the intensity of the pain being experienced by the individual; and $(v)$ reduce back pain-related disability. ${ }^{42}$ These goals should be carried out simultaneously, rather than being placed in any particular order with one goal having more status or importance.

With any rehabilitation process the key element is individualisation, as each individual is unique and has unique needs when it comes to rehabilitation. This has important implications in the rehabilitation process because no two low back cases are alike and therefore a standardised exercise prescription cannot be given. Yet certain exercise modalities are generally prescribed in the literature as being beneficial for a specific population. In the end no exercise modality can lay claim that it is more beneficial to another, as it is what is right for the individual that counts the most. With low back pain there is an increased variability around the nature and degree of the motor control problems. ${ }^{32}$ In a clinical situation this variability between individuals means that there needs to be an individualised problemsolving approach to the neuromuscular dysfunction rather than a 'one-size-fits-all' approach to prescription. ${ }^{32}$

It is important to differentiate between treatment and prevention when considering injuries to the low back. Treatment occurs after the injury has happened, while prevention reduces the risk of the injury occurring.
It is critical to note that the following section is a guideline to the prevention of low back injuries. It is not possible to use this as a generalised template for treatment because no two injuries are the same. If there is any doubt over a spinal injury it is important to consult with a specialist, as certain injuries to the low back can have serious consequences if not treated appropriately.

These guidelines are aimed towards the prevention of injuries rather than the treatment. For the treatment of injuries it is best to seek the guidance of a physiotherapist or biokineticist.

\section{The role of exercise (Table I)}

There are currently a wide range of available exercises prescribed for the prevention and treatment of low back-related disorders, despite the fact that many have not been validated or scientifically studied. ${ }^{1}$ Most studies indicate that physical activity is a valuable therapeutic approach; however, there is no agreement on the specific technique, intensity, or type of exercise. ${ }^{3}$ When reviewing the research it is clear that there is no evidence in favour of one particular exercise modality over another due to the contradictory nature of the results. ${ }^{49}$ This is an important finding because many rehabilitation programmes claim to be the best method for the treatment and prevention of low back injuries even though there is insufficient evidence to support their superiority. ${ }^{3}$ The best rugby-specific protocol for preventing low back injuries should therefore be to find a balance between exercise modalities, and not concentrate on just one particular mode.

Most rugby players are involved in some form of strength training programme to enhance their sporting performance and reduce the risk of injury. These exercise programmes often involve weight training to facilitate speed, strength, power, endurance, as well as muscular hypertrophy. The spine benefits from this type of training because the weight training indirectly strengthens the local support system. ${ }^{33}$ Furthermore, there is sufficient scientific evidence to support exercise programmes which combine multiple aspects of fitness including strength training, flexibility and cardiovascular fitness. ${ }^{3}$ As a result there is nothing wrong with using general exercise as part of an exercise protocol to prevent spinal injuries.

It is not known if core stabilisation exercises are the most appropriate exercises or if other exercises are equal or superior in reversing the motor control of the deep trunk-stabilising muscles. ${ }^{32}$ Some evidence suggests that general exercise and strength training on its own can be sufficient for conditioning the stabilisers of the low back. ${ }^{33}$ This research is controversial because it claimed that there is no benefit in adding exercises that place an emphasis on retraining of the core. The findings were that there was a functional difference in the relative recruitment of the abdominal muscles between general strength exercises, such as weight training, and stabilisation exercises, such as Pilates. ${ }^{14}$ Individuals who had a predisposition for low back-related injuries were found to activate selected abdominal muscles at low levels of their maximum ability, but following a resistance training programme these individuals could recruit a much greater percentage of their maximum. ${ }^{14}$ From a clinical point of view this implies that general exercise, if performed correctly, may be sufficient to activate the local stabilising system in parallel with the global mobilising muscles.

However, the strength training regimens that rugby players use place most of the emphasis on the global mobilising muscles rather than the local stabilising muscles. The global muscle system (mobilisers) includes the muscles that produce noticeable movement. Some of these muscles also have a limited stabilisation role. These muscles are generally larger, stronger and take longer to fatigue. 


\begin{tabular}{|c|c|c|c|c|c|}
\hline Author & Groups & Duration & $\begin{array}{c}\text { Effectiveness } \\
\text { criteria }\end{array}$ & $\begin{array}{l}\text { Outcome } \\
\text { measures }\end{array}$ & Outcome \\
\hline \multirow[t]{3}{*}{$\begin{array}{l}\text { Hansen et al. } \\
(1993)^{21}\end{array}$} & $\begin{array}{l}\text { Dynamic back } \\
\text { muscle exercises }\end{array}$ & 4 weeks & Reduction in pain & $\begin{array}{l}0 \text { - } 9 \text { visual interval } \\
\text { scale for pain }\end{array}$ & $\begin{array}{l}\text { Outcome based on sub- } \\
\text { groups within the low } \\
\text { back pain population }\end{array}$ \\
\hline & $\begin{array}{l}\text { Conventional } \\
\text { physiotherapy }\end{array}$ & & & & \\
\hline & Placebo & & & & \\
\hline \multirow{6}{*}{$\begin{array}{l}\text { Koumantakis } \\
\text { et al. (2005) }\end{array}$} & Specific muscle & 8 weeks & Improved & VAS pain score & No differences detected \\
\hline & $\begin{array}{l}\text { stabilisation } \\
\text { exercise }\end{array}$ & & functional ability & $\begin{array}{l}\text { McGill pain } \\
\text { questionnaire }\end{array}$ & \\
\hline & General & & & $\begin{array}{l}\text { Roland-Morris } \\
\text { disability questionnaire }\end{array}$ & $\begin{array}{l}\text { Both groups improved } \\
\text { functional ability }\end{array}$ \\
\hline & exercise only & & & $\begin{array}{l}\text { Tampa scale of } \\
\text { kinesiophobia }\end{array}$ & Physical exercise alone \\
\hline & & & & $\begin{array}{l}\text { Pain self-efficacy } \\
\text { questionnaire }\end{array}$ & $\begin{array}{l}\text { is the determinant for } \\
\text { improvement, not the }\end{array}$ \\
\hline & & & & $\begin{array}{l}\text { Pain locus of } \\
\text { control scale }\end{array}$ & exercise type \\
\hline \multirow[t]{3}{*}{$\begin{array}{l}\text { O'Sullivan } \\
\text { et al. (1998) }\end{array}$} & $\begin{array}{l}\text { Specific stabilising } \\
\text { exercise }\end{array}$ & 10 weeks & & & $\begin{array}{l}\text { Reduction in pain and } \\
\text { functional disability for the }\end{array}$ \\
\hline & & & $\begin{array}{l}\text { Reduction in } \\
\text { functional disability }\end{array}$ & $\begin{array}{l}\text { Oswestry low back } \\
\text { disability } \\
\text { questionnaire }\end{array}$ & $\begin{array}{l}\text { specific stabilisation group } \\
\text { after } 30 \text { month follow-up }\end{array}$ \\
\hline & $\begin{array}{l}\text { General } \\
\text { practitioner }\end{array}$ & & & & $\begin{array}{l}\text { No significant change for the } \\
\text { general practitioner group }\end{array}$ \\
\hline \multirow{6}{*}{$\begin{array}{l}\text { Seferlis } \\
\text { et al. (1998) }\end{array}$} & Intense exercise & 6 weeks & Reduction in pain & VAS pain score & Improved global back pain \\
\hline & & & $\begin{array}{l}\text { Reduction in functional } \\
\text { disability }\end{array}$ & $\begin{array}{l}\text { Oswestry low back } \\
\text { pain disability } \\
\text { questionnaire }\end{array}$ & $\begin{array}{l}\text { Improved functional } \\
\text { ability and performance }\end{array}$ \\
\hline & Manual therapy & 12 months & $\begin{array}{l}\text { Treatment } \\
\text { satisfaction }\end{array}$ & $\begin{array}{l}\text { Oswestry low back } \\
\text { pain disability } \\
\text { questionnaire }\end{array}$ & $\begin{array}{l}\text { Improvements in pain, } \\
\text { functional ability, } \\
\text { impairment, socio- } \\
\text { economic disability }\end{array}$ \\
\hline & Intensive training & & $\begin{array}{l}\text { Improvement } \\
\text { in impairment }\end{array}$ & Modified Borg & in all groups \\
\hline & General practitioner & & Improvement in pain & 10-point scale & \\
\hline & & & $\begin{array}{l}\text { Improvement in } \\
\text { functional ability } \\
\text { Improvement in } \\
\text { socio-economic disability }\end{array}$ & $\begin{array}{l}\text { Carlsson's pain } \\
\text { questionnaire }\end{array}$ & $\begin{array}{l}\text { Least satisfaction with } \\
\text { general practitioner } \\
\text { treatment }\end{array}$ \\
\hline
\end{tabular}

The local stabilising system comprises muscles that act at a defined location to limit undesirable movement. In most cases the stabilising muscles are not trained to the same extent as the global system and as a result are often weaker and fatigue easier.

Recently the term 'core' has become very popular in exercise therapy. The core is a collection of muscular structures which form a corset/brace that functions as a support for the spine. ${ }^{2}$ In theory it is cylindrical in shape, made up of the pelvic floor at the bottom, the abdominals at the front and sides, the diaphragm at the top, and the spinal muscles at the back. The core functions like an internal weight belt because the muscles involved contract together to increase the internal pressure of the abdomen, and hence the stiffness around the lumbar spine. To visualise the role of the core imagine a soft drink can. When the can is open the thin aluminium sides can be crushed easily. When the can is closed and pressurised it is not possible to distort the shape of the can. In the case of the core, this increase in pressure is associated with an increase in muscle thickness due to muscular contraction, and is not due to the Valsalva manoeuvre (breath holding).

Exercise programmes that address trunk muscle recruitment strategies are recommended for training the local stabilising system, especially if they include the relative activation levels of specific abdominal muscles. ${ }^{45}$ Core stabilisation is one exercise modality that focuses on the local stabilising musculature such as the transversus 
abdominus. Core stabilisation is a term that has become synonymous with stabilisiation around the lumbar spine and is often referred to as core stability or core strengthening. In essence core stability is used as a broad term to encompass any exercise which requires muscular control around the lumbar spine to maintain functional stability. ${ }^{2}$ In other words, it is the ability of the lumbo-pelvic complex to prevent deformation and to return to equilibrium after perturbation. 50

Core stabilisation exercises have been promoted for lumbar stabilisation and for preventing or rehabilitating low back-related injuries because they focus on the activation of key supporting and stabilising muscles. Certain key muscles have been highlighted as essential muscles involved in core stability, as their structure, function and location fulfil a supporting role for the spine. Researchers have also found that the core muscles are controlled directly by the brain and activate prior to any movement. Deep stabilising muscles are therefore fundamental in the central nervous system control of trunk stability and act as the centre of the functional kinetic chain. Training the spinal stabilising muscles will therefore help to maintain a healthy, pain-free low back as they provide greater segmental control and support for the spine.

Training of the transversus abdominus is effective in the management of low back pain, as it has been shown to be the principal abdominal muscle affected. ${ }^{25}$ The transversus abdominus has been shown to contract tonically as it produces constant tension that is maintained at a low level. ${ }^{24}$ As a result of the loss in tonic function in low back pain, specific retraining is required to regain normal function. It is recommended that this retraining be performed independently of other trunk muscles. ${ }^{25}$

Simple stabilisation exercises have been shown to be effective in activating the abdominal muscles such as the transversus abdominus. ${ }^{5}$ Isolated activation of the transversus abdominus is achieved by the inward movement of the lower abdominal wall while in the supine position in an abdominal hollowing manoeuvre, ${ }^{48}$ as well as by specific respiratory manoeuvres. ${ }^{26}$

\section{Conclusion}

A rugby player will have increased core stability/strength and a reduced risk of injury if the internal support mechanisms of the spine have been conditioned to resist distortion or injury from external forces. Not only will improved core stability benefit players on the field during matches or practices, it will also assist in preventing unnecessary injuries during weight training and pre-season conditioning. Simply adding selected core stability exercises to a rugby player's exercise routine will reduce the risk of injuries to the low back and core. It is important to clarify that it is insufficient to only train one aspect of the core, as is often the case. There is a great misconception that by performing numerous crunches and sit-ups the core will be strengthened. In fact, the opposite can be true because by overloading one aspect of the stabilising system you leave the other areas vulnerable and weak, which is why an intricate balance of exercises is required to target all muscles involved in spinal stability.

If the injury rate to the low back and core is to be reduced, coaches and conditioning experts need to implement the best practice guidelines outlined in this article. The take-home message is that adequate stabilisation of the spine is the key factor in the prevention of injuries to the low back and core. This stabilisation is important to prevent hypermobility and loss of control around the lumbar spine.

It is for this reason that exercise programmes that combine core stability with general strength training should be prescribed for rugby players to prepare them for the level of impact involved in the game, as well as for sport-related weight training and non-sporting-related daily activities.

\section{Acknowledgements}

The paper was commissioned by the BokSmart programme, which is a national programme sponsored by ABSA and implemented on behalf of the South African Rugby Union and the Chris Burger/Petro Jackson Player's Fund. The goal of the programme is to teach safe and effective techniques, which will reduce the incidence and severity of injury, make the game safer for all involved and improve rugby performance.

\section{REFERENCES}

1. Abenhaim L, Rossignol M, Valat J-P, et al. The role of activity in the therapeutic management of back pain: Report of the International Paris Task Force on Back Pain. Spine 2000; 25: 1s-33s.

2. Akuthota V, Nadler SF. Core strengthening. Arch Phys Med Rehabil 2004; 85: s86-s92.

3. Albright J, Allman R, Bonfiglio RP, et al. Philadelphia panel evidencebased clinical practice guidelines on selected rehabilitation interventions for low back pain. Bone Joint 2001; 81: 1641-74.

4. Allison GT, Godfrey P, Robinson G. EMG signal amplitude assessment during abdominal bracing and hollowing. J Electromyogr Kinesiol 1998; 8: 51-7.

5. Arokoski JP, Valta T, Airaksinen O, Kankaanpaa M. Back and abdominal muscle function during stabilization exercises. Arch Phys Med Rehabil 2001; 82: 1089-98.

6. Bathgate A, Best JP, Craig G, Jamieson M. A prospective study of injuries to elite Australian rugby union players. Br J Sports Med 2002; 36: 265-9.

7. BergmarkA. Stability of the lumbar spine. A study in mechanical engineering. Acta Orthop Scand Suppl 1989; 230: 1-54.

8. Brooks JH, Fuller CW, Kemp SP, Reddin DB. Epidemiology of injuries in English professional rugby union: Part 1 match injuries. Br J Sports Med 2005; 39: 757-66.

9. Brooks JH, Kemp SP. Recent trends in rugby union injuries. Clin Sport Med 2008; 27: 57-73.

10. Brukner P, Khan K. Clinical Sports Medicine. 2nd ed. North Ryde: McGraw-Hill, 2005.

11. Clark DR, Roux C, Noakes TD. A prospective study of the incidence and nature of injuries to adult rugby players. S Afr Med J 1990; 77: 559-62.

12. Cresswell AG, Grundstrom H, Thorstensson A. Observations on intraabdominal pressure and patterns of abdominal intra-muscular activity in man. Acta Physiol Scand 1992; 144: 409-18.

13. Cresswell AG, Oddsson $L$, Thorstensson $A$. The influence of sudden perturbations on trunk muscle activity and intra-abdominal pressure while standing. Exp Brain Res 1994; 98: 336-41.

14. Daneels LA, Coorevits PL, Cools AM, et al. Differences in electromyographic activity in the multifidus muscle and the iliocostalis lumborum between healthy subjects and patients with sub acute and chronic low back pain. Eur Spine J 2002; 11: 13-9.

15. Descarreaux M, Normand MC, Laurencelle L, Dugas C. Evaluation of a specific home exercise program for low back pain. J Manipulative Physiol Ther 2002; 25: 497-503

16. Fryer G, Morris T, Gibbons P. Paraspinal muscles and intervertebral dysfunction: Part one. J Manipulative Physiol Ther 2004; 267-74.

17. Fuller $\mathrm{CW}$, Brookes JH, Kemp SP. Spinal Injuries in professional rugby union: A prospective cohort study. Clin J Sports Med 2007; 17: 10-6.

18. Fuller CW, Brooks JH, Cancea RJ, Hall J, Kemp SP. Contact events in rugby union and their propensity to cause injury. Br J Sports Med 2007; 41: 862-7.

19. Garraway WM, Lee AJ, Macleod DAD, Telfer JW, Deary IJ, Murray GD. Factors influencing tackle injuries in rugby union football. Br J Sports Med 1999; 33: 37-41.

20. Gianotti S, Hume P, Hopkins W, Harawira J, Truman R. An interim evaluation of the effect of a new scrum law on neck and back injuries in rugby union. Br J Sports Med 2008; 42: 427-30.

21. Hansen FR, Bendix T, Skov $\mathrm{P}$, et al. Intensive, dynamic back-muscle exercises, conventional physiotherapy, or placebo-control treatment of low-back pain. Spine 1993; 18: 98-108. 
22. Hayden JA, Van Tulder MW, Malmivaara AV, Koes BW. Meta-analysis: Exercise therapy for nonspecific low back pain. Ann Intern Med 2005; 142: 765-75.

23. Hides JA, Richardson CA, Jull GA. Multifidus muscle recovery is not automatic after resolution of acute, first-episode low back pain. Spine 1996; 21: $2763-9$.

24. Hodges P. Dealing with the challenges to spinal stability: The mechanisms of motor control of the trunk. In: Singer KP, ed. IFOMT 2000; 206-15. University of Western Australia, Perth, Australia. IFOMT. Proceedings of University of Western Australia, Perth, Australia. IFOMT. Proceedings of
the 7 th Scientific Conference of the IFOMT in conjunction with the MPAA. 2000.

25. Hodges PW. Is there a role for transversus abdominus in lumbo-pelvic stability? Man Ther 1999; 4: 74-86.

26. Hodges PW, Gandevia SC, Richardson CA. Contractions of specific abdominal muscles in postural tasks are affected by respiratory maneuvers. J Appl Physiol 1997; 83: 753-60.

27. Hodges PW, Richardson C. Feedforward contraction of transversus abdominus is not influenced by the direction of arm movement. Exp Brain Res 1997; 114: 362-70.

28. Hodges PW, Richardson CA. Inefficient muscular stabilization of the lumbar spine associated with low back pain. A motor control evaluation of transversus abdominis. Spine 1996; 21: 2640-50.

29. Hodges PW, Richardson CA. Contraction of the abdominal muscles as sociated with movement of the lower limb. Phys Ther 1997; 77: 132-42.

30. Indahl A. Low back pain: diagnosis, treatment, and prognosis. Scand $J$ Rheumatol 2004; 33: 199-209.

31. Indahl A, Velund L, Reikeraas $\mathrm{O}$. Good prognosis for low back pain when left untampered. A randomized clinical trial. Spine 1995; 20: 473-7.

32. Jull GA, Richardson CA. Motor control problems in patients with spinal pain: a new direction for therapeutic exercise. J Manipulative Physiol Ther 2000; 23: 115-7.

33. Koumantakis GA, Watson PJ, Oldham JA. Supplementation of general endurance exercise with stabilisation training versus general exercise only. Physiological and functional outcomes of a randomised controlled trial of patients with recurrent low back pain. Clin Biomech 2005; 20: 474 82.

34. Kreighbaum E, Barthels KM. The Vertebral Column. Biomechanics: $A$ Qualitative Approach for Studying Human Movement. Nedham Heights, MA: Allyn \& Bacon: Pearson Education, 1996: 238-44.

35. Lee AJ, Garraway MW, Arneil DW. Influence of preseason training, fitness, and existing injury on subsequent rugby injury. $\mathrm{Br} J$ Sports $\mathrm{Med}$ 2001; 35: 412-7.
36. Makan P. Spinal injuries. In: Nicol A, Steyn E eds. Handbook of Trauma for Southern Africa. New York: Oxford University Press, 2004: 156-62.

37. Milburn PD. Biomechanics of rugby union scummaging: technical safety issues. Sports Med 1993; 16: 168-79.

38. Noakes TD, Jakoet I, Baalbergen E. An apparent reduction in the incidence and severity of spinal cord injuries in schoolboy rugby players in the Western Cape since 1990. S Afr Med J 1999; 89: 540-5.

39. O'Sullivan PB, Twomey L, Allison GT. Altered abdominal muscle recruitment in patients with chronic back pain following a specific exercise intervention. J Orthop Sports Phys Ther 1998; 27: 114-24.

40. Panjabi MM. The stabilizing system of the spine. Part I. Function, dysfunction, adaptation, and enhancement. J Spinal Disord 1992; 5: 383-9.

41. Panjabi MM. Clinical spinal instability and low back pain. $J$ Electromyo Kinesiol 2003; 13: 371-9.

42. Rainville J, Hartigan C, Martinez E, Limke J, Jouve C, Finno M. Exercise as a treatment for chronic low back pain. Spine 2004; 4: 106-15.

43. Roux CE, Goedeke R, Visser GR, Van ZyI WA, Noakes TD. The epidemiology of schoolboy rugby injuries. S Afr Med J 1987; 71: 307-13.

44. Seferlis T, Nemeth G, Carlsson AM, Gillstrom P. Conservative treatment in patients sick-listed for acute low back pain: A prospective randomised study with 12 months follow-up. Eur Spine J 1998; 7: 461-70.

45. Silfies SP, Squillante D, Maurer P, Westcott S, Karduna AR. Trunk muscle recruitment patterns in specific chronic low back pain populations. Clin Biomech 2005; 20: 465-73.

46. Souza GM, Baker LL, Powers CM. Electromyographic activity of selected trunk muscles during dynamic spine stabilization exercises. Arch Phys Med Rehabil 2001; 82: 1551-7.

47. Strydom Z, Faure M, Bester MM. Private practitioners use of exercise therapy in low back pain. SA J Physiother 2005; 61: 3-7.

48. Urquhart DM, Hodges PW, Allen TJ, Story $\mathrm{IH}$. Abdominal muscle recruitment during a range of voluntary exercises. Man Ther 2004; 1-10.

49. Van Tulder MW, Koes BW, Bouter LM. Conservative treatment of acute and chronic nonspecific low back pain: A systematic review of randomised controlled trials of the most common interventions. Spine 1997 22: $2128-56$

50. Willson JD, Dougherty CP, Lloyd Ireland M, McClay Davis I. Core stability and its relationship to lower extreme function and injury. Am Acad Orthop Sur 2005; 13: 316-25. 